\title{
Comparative Study on the Piano Method Books for Undergraduate's Non-Piano Majors
}

\author{
Zakaria, J.* and Mahzair, A.M. \\ University Teknologi MARA, Malaysia
}

\begin{abstract}
A comparative study was carried out on a selected two method books for undergraduate's non-piano majors in the group piano instruction (hereafter as GPI). This method book chosen for this study as it is the most practiced in Malaysia; 1) Alfred's Basic Adult Piano Course, Adult All-In-One (2011) by Palmer, Monus and Lethco; and 2) Faber's Adult Piano Adventures All-In-One (2002) by Faber and Faber. The objectives of this paper are to analyze 1) the similarities and difference; and 2) the strength and weakness on each method books. This study examined the relationship towards attaining the course learning outcomes for GPI. Qualitative content analysis (comparative approach) was adopted. Findings show that ninety percent are addressed in rhythm, melodies, chord progression and harmonization, transposition, and improvisation using Faber, while Alfred indicated seventy-five percent towards achieving the first course learning outcome. Works for solo piano music is delivered and assessed except for ensemble piano music for both methods. This leads towards the attainment for the second learning outcomes. The significance of Faber method provides sight-reading exercise while Alfred does not. Alfred progress quickly and adequate for undergraduate non-piano majors as they had a basic musical knowledge and skills. Meanwhile, Faber promotes students' engagement and interactive learning; and student should be able to demonstrate the desired essential musical skills. In conclusion, both methods are relevant to the (GPI); however, the study also revealed that instruction through one method alone scarcely to match the GPI's intended learning outcomes due to various strengths and weaknesses of each methods. Hence, it is recommended for a future in-depth research to be carried out to investigate the effectiveness of these two methods to support this study.
\end{abstract}

Keywords: Piano method book, group piano instruction, non-piano major undergraduate, piano pedagogy

\section{Piano Proficiency and the Significances}

Piano proficiency or keyboard skills is the most important skills for all music students to acquire and master regardless of what instrument they are majoring in (Amoriello, 2010). Mastery of piano skills is proven and useful for all music teachers and students in teaching-learning. Past studies had proven the importance of the piano proficiency skills for music students, Findings had also posited that learning basic piano helps non-piano majors to develop their instrument skills, improve note reading, have strong rhythmic skills, strengthen theory and aural skills, enhance performance and musicianship skill as well as build up other related skills such as transposing, harmonizing, accompanying, teaching, composing and improvising.

The institutions of higher learning in Malaysia offering music programmes generally enlisted basic piano proficiency skills as a mandatory for all music majors to fulfil the degree requirement. The skills set in proficiency skills are namely: 1) scales; 2) arpeggios; 3) chords and cadence; 4) repertoires; 5) harmonization; 6) transposition; 7) improvisation and 8) sight-reading. Mastery of these eight techniques is up most useful for music students to be able to utilise and relate these techniques and playing skills with their major instrument study and other music courses such as theory, aural, arranging, modern harmony and composition. For instance, piano proficiency helps composition students to compose and arrange their work easily. These abilities and skills will prepare them to be well-rounded musicians (Bianchi, 1978).) Bianchi added that these students may have better job opportunity as a music teacher when they possess both piano skills and their major instrument. 
This is supported by Young (2013), she mentioned that faculty members, performers and educators mostly carry out similar musical activities had comparable piano proficient and utilized similar piano skills in their career. Finally, Callahan in 2005 emphasized that students tend to learn and adapt the music theory and aural skills course much faster with the aid and usage of the keyboard in their learning.

This study is carried out in one purposively selected public university in Malaysia that offers music programme for both undergraduate and postgraduate students. Its Faculty of Music mandates piano proficiency skills for all non-piano majors in all undergraduate programmes, namely: 1) Diploma in Music, 2) Bachelor in Music Education, 3) Bachelor of Music Composition, 4) Bachelor of Music Performance, and 5) Bachelor of Music Business. These programmes provide a total of two semester of GPI course known as "Keyboard Skills". This course is intended to acquaint students with the utilization of music through piano proficiency. Both theoretical and practical aspects of music will be applied including score reading, scales, arpeggios, chord realization, harmonization, transposition, and improvisation. Therefore, the next chapter will briefly discussion on the GPI's history, formats, syllabus, significance, and the benefits.

\section{Group Piano Instruction among Undergraduate's Non-Piano Majors}

Group Piano Instruction (hereafter as GPI) or group piano lessons are course catered for group learning. The GPI learning originated in early nineteenth century (Richards 1962) and continues as a widely used method for piano instruction delivery. Group lesson was designed for young children below the age of five, master classes and adult piano beginners. Unlike individual one-to-one lesson, group piano lesson usually is conducted by one teacher with $10-30$ students in the group (Young, 2013).

Johan Bernhard Logier initiated this system of teaching. His primary motivation for the group teaching system was simply economic (Chiu, 2017). The main objective of the group learning is to master music theory and keyboard theory rather than developing advanced technique (Rainbow, 1990). This teaching methodology was widely practiced in the United States and Britain due to cost affordability and learning effectiveness. According to Beres (1999), the GPI and the Music Teachers National Association and Roland Corporation support the philosophy of group instruction setting in piano teaching delivery. Columbia University adopted this methodology for their piano classes for adults in 1930s - 1940s (Skroch, 1991). With the onset development of the electronic piano laboratory in 1950s (Schons, 2005), group instruction delivery was used the college level (Kowalchyk, et al. 1997). When the GPI were first introduced into college level, the purpose of the course is to focus mainly on developing piano techniques and teach standard piano literature. After few decades, the syllabus had improved covering mastering other functional piano skills.

Fischer (2010) highlighted four main skills were acquired by students from the GPI: reading, transposing, harmonizing, and transposing. It was proven that the GPI methodology assisted non-piano music majors to increase their understanding and knowledge on the musical fundamental such as theoretical and aural skills (Lancester, et al.1955); developed strong rhythmic skills (Kowalchyk, et al.1997); encouraged musicianship (Nakagawa, 2007) and "increased knowledge of repertoire, improved listening skills, better technique, enhance musical sensitivity and greater creativity and independence of thought" (Johnson, 1981). The recent study carried out in 2018 in a local public university by Zakaria, et al (2018) has also postulated that the GPI has positive influences and effects on the other musical related skills such as composing, teaching and enhance interpersonal and social skills. Advocates for the GPI among music undergraduates have stated that it is the "most effective and efficient tool" for enabling students to be independent learners so they can continue to make music for a lifetime (Amorielo, 2016). In addition, finding of this study indicated that majority of the music nonpiano major students (respondents) agreed to the music theory and performing exposure in the GPI; learning more sight-reading and to carry out simple composition in the GPI. 
These suggested areas to be considered to include into the GPI for continual improvement in the course curriculum design and content for the near future to suit the students' needs and aspirations. With this finding, it leads to a discussion on the method books available that provides the best teaching and learning method for both lecturers and students and supporting the program learning outcome simultaneously.

\section{Piano Method Books}

In musical term, the word "Piano Method" refers to key concepts and step-by-step learning which is written in a piano instruction book. Piano method presents an organized plan for learning to facilitate learning and progress of students through the beginning stages of piano instruction. (Chen, et al. 2013). Number of past studies have revealed that the content of the piano method mostly encompasses; list of selected repertoires, music notations and rhythms, scale/arpeggios/chord, hand positions, fingering charts, pedaling, technical exercises, musical form, as well as other important musical elements such as articulation, dynamic, phrasing, tempo, style and expression.

Piano teaching methods are derived from Carl Czerny (1791-1857). A scholar, Fuchs in 2009 stated that Czerny he was the first composer to include fingerings in his music. This was shown in the letter by Czerny: “...I wrote every melody and passage considering the good posture, right fingering, good stops and smooth performance of the student...." (Czerny). Carl Czerny rendered fingering integral to the artistic process (Swinkin, 2007) and wrote a library of teaching pieces later in his life. In the mid to late 1800s, great teachers namely Leschetitsky and Liszt shared the same schools of thought whom created the emerging romantic pieces that presented as a breakthrough in setting an entirely new demand to the pianist and teacher ("Passing of The world's Most Famous Piano Teacher", (1915). Thereafter, the "Golden Age of the Piano in 1925 saw the onset era with newly emerged methods with creative learning approach for easy practical or hands on piano lessons. However, the methods from John Schaum and John Thompson are still being used. The newer modern versions of Alfred, Hal Leonard and the Faber series also integrate both the learning approaches. (Hall, n.d)

Even though each method book is compiled differently, common lessons on techniques, music theory, piano fundamentals, and learning exercises are included. Therefore, the purpose of this study is to carry out a comparative study on two (2) purposively selected piano methods which are significant for undergraduate's non-piano majors in the GPI courses. The comparative study used content analysis of these two method books: 1) Alfred's Adult All-In-One (2011) by Palmer, Monus and Lethco, and 2) Faber's Adult Piano Adventures AllIn-One (2002) by Faber and Faber.

The qualitative content analysis (comparative approach) was adopted to review and addresses the similarities and differences, the strength, and the weakness on each selected method books. Additionally, the progression of material in these methods in the three main areas, namely: 1) lesson, 2 theory and 3) technique shall be highlighted. The significance of this study shall benefit the lecturers teaching piano educational program in the higher institution on the various pedagogical teaching methods applicable for the students.

\section{Overview Summary on Each Method Book:}

Alfred's Basic Adult Piano Course: Adult All-In-One Course: Lesson-Theory-Technic: Level 1- includes lesson, theory, and technique in a convenient, "all-in-one" format. This comprehensive course adds such features as isometric hand exercises, finger strengthening drills, and written assignments that reinforce each lesson's concepts. There is a smooth, logical progression between each lesson, a thorough explanation of chord theory and playing styles, and outstanding extra songs, including folk, classical, and contemporary selections. (Palmer, Manus, Lethco, 2005)

Faber Piano Adventures: Adult Piano Adventures All-in-One -Lesson Book 1- includes lessons, technique, and theory in a single volume for ease of use. Book 1 presents the fundamentals of music notation, chord playing, 
and musical form. The redesigned layout improves information hierarchy, putting focus on key concepts and step-by-step learning. (Faber, Faber, 2016)

\section{Finding and Analysis}

This first section fulfils the first research objective on the similarities and difference of each method. Content analysis of Alfred's and Faber's Adult All-In-One methods was carried out; and the findings are elaborated in three main categories, namely: 1) lesson, 2) technique and 3) music theory.

\section{General Content Analysis}

Firstly, the content analysis shows that Faber provides a total of sixteen chapters as compared to Alfred with only thirteen chapters. Faber offers more technique covered such as transposition, improvisation, and sightreading exercise. Both methods covered equal theory lessons except Faber has additional topics on ear training, rules of stems, technical name (scale degree) and musical terms. Analysis is shown in Table 1 below:

Table 1: General Content Analysis

\begin{tabular}{|c|c|c|}
\hline & ALFRED & FABER \\
\hline Lesson & $\begin{array}{l}\text { Introduction to Playing } \\
\text { C Position } \\
\text { The Grand Staff } \\
\text { Playing C-G on the Grand Staff } \\
\text { Introduction to Chords } \\
\text { G Position } \\
\text { Middle C Position } \\
\text { Expanding the 5-Finger Position } \\
\text { Scale \& Chords- The Key of C Major } \\
\text { Scale \& Chords- The Key of G Major } \\
\text { Scale \& Chords- The Key of F Major } \\
\text { Scale \& Chords- The Key of A Minor } \\
\text { Scale \& Chords- The Key of D Minor }\end{array}$ & $\begin{array}{l}\text { Introduction to Playing } \\
\text { Orientation to the Staff } \\
\text { Reading Reinforcement } \\
\text { More about Staff Reading } \\
\text { More Bass Clef Note Reading } \\
\text { Eighth Notes } \\
\text { Treble Space Notes: F-A-C-E } \\
\text { Treble C Penta-scale } \\
\text { G Penta-scales in } 3 \text { Locations } \\
\text { Sharps and Flats } \\
\text { Intervals: 4ths, 5ths, 6ths } \\
\text { The C Major Scales } \\
\text { The G7 Chord } \\
\text { Primary Chords in C Major: I-IV-V7 } \\
\text { The G Major Scale } \\
\text { Primary Chords in G Major: I-IV-V7 }\end{array}$ \\
\hline Technique & $\begin{array}{l}\text { Rhythmic Exercise } \\
\text { Study/Warm up Exercise (Intervals, } \\
\text { Chords, Hanon) } \\
\text { Arpeggios } \\
\text { Developing equal skills with all fingers } \\
\text { Scale } \\
\text { Overlapping pedal }\end{array}$ & $\begin{array}{l}\text { Transposition } \\
\text { Rhythmic Exercise } \\
\text { Improvisation } \\
\text { Study/Warm up Exercise (Intervals, Chords, } \\
\text { Penta-scale, Octave, } \\
\text { Accidentals) } \\
\text { Sight Reading Exercise } \\
\text { Arpeggios } \\
\text { Scale }\end{array}$ \\
\hline Theory & $\begin{array}{l}\text { Naming the notes } \\
\text { Time Signature } \\
\text { Intervals } \\
\text { Chord Symbol } \\
\text { Slur and Ties } \\
\text { Writing accidentals }\end{array}$ & $\begin{array}{l}\text { Naming the notes } \\
\text { Ear Training } \\
\text { Time Signature } \\
\text { Intervals } \\
\text { Rule for Stems } \\
\text { Chord Symbol }\end{array}$ \\
\hline
\end{tabular}




\begin{tabular}{|l|l}
\hline Half step and whole step & scales \\
Scales & Triads/Chords \\
Triads/Chords & Technical name (scale degree) \\
& Musical Terms \\
\hline
\end{tabular}

\section{Comparative Analysis on Feature}

Further analysis is made by comparing the features such as hand and fingering placement, keyboard chord chart, scale chart, chord symbol, dictionary, online support, and teacher duet as shown in Table 2.

Table 2 Comparative Analysis on Features

\begin{tabular}{lll}
\hline & ALFRED & FABER \\
\hline Number of pieces & 80 & 64 \\
\hline Price & US \$16.99 & US \$19.99 \\
\hline Tevel available & $1,2,3$ & 1,2 \\
\hline Fingering placement & 159 & 184 \\
\hline Keyboard Chord Chart & Display & Display \\
\hline Scale chart & Display & Display \\
& 1 Octave scale & Penta-scale: \\
\hline Chord symbol & C, G, F, Am, Dm & C, G, D, A, E, B, F\#, Gb, \\
& & Db, Ab, Eb, Bb, F \\
\hline Dictionary & Pop symbol & Pop symbol \\
\hline Online/Audio support & & Roman numerals \\
\hline Optional teacherduets & No & Yes \\
\hline Certificates ofAwards & No & Website (free) \\
\hline
\end{tabular}

Alfred consists of eighty pieces, with the book price of US \$16.99 and contains three levels with 159 pages. Faber costs US \$ 19.99, consisting of sixty-four pieces with two levels with 184 pages. Analysis shows that both methods displayed the fingering placement and keyboard chord chart. Alfred provides scale chart on the C, G F, A harmonic minor and D harmonic minor. In contrast, Faber includes all twelve major penta- scale charts at the end page of the book. While Alfred utilises only pop symbol, Faber utilises pop and Roman numeral symbol. One added value of Faber is the dictionary on the musical terms; this is the best features of Faber. It appeared at the end page of the book. Faber also offers more features such as free online support through website and Appstore; and optional teacher duets for accompaniment. One of the distinctive offerings of Alfred is provision of certificate of awards after completing the book.

\section{Comparative Analysis on Musical Elements}

Next, musical elements such as note reading, rhythm/note value, time signature, intervals, articulations, scales, chords, key signatures, and dynamic were examined between Alfred and Faber.

Faber provides three types of note reading concepts namely: 1) pre-reading, 2) grand staff and 3) lead-sheet. Faber introduced four note values (crotchet, minim, dotted minim, and semibreve) at once on the second piece of the lesson. Faber only covered until quaver on the piece number 21 onwards. As of time signature, Faber only has $3 / 4$ and $4 / 4$. 
Alfred provides staff and grand staff as a note reading concept. It introduces crotchet and minim on the first piece, followed by semibreve on the second piece and dotted minim started on the piece number 18 onwards. In the middle and towards the end of the lesson, Alfred introduced quaver, dotted crotchet, triplets quaver and swing rhythm. In terms of time signature, Alfred provides 2/4, 3/4 and 4/4/. It is found that Alfred has covered intervals between the range from 2 nd to $8 \mathrm{ve}$.

Both methods have provided equal lesson on the articulations. Scale-wise, Alfred provides total of five types of an octave scale (C Major, G Major, F major, A harmonic minor and D harmonic minor). In contrast, Faber provides three types of Penta scale (C Major, G Major an A Major), only two types of an octave scale (C Major and G Major) and a chromatic scale.

Finding also shows that, both methods provide lesson on chord I, IV and V7, with additional chord Sus4 in the Faber. In addition, Alfred provides more key signatures compare to the Faber. In terms of dynamic, both methods have the similar types of dynamic except Alfred has additional dynamic (ff and pp). It is found that Alfred has more intervals covered (between the range from 2nd to 8ve), meanwhile, Faber is only up covered until the interval of 6th.

Table 3 presents the differences between the two musical elements in each books,

Table 3 Comparative Analysis on Musical Elements

\begin{tabular}{lll}
\hline & ALFRED & FABER \\
\hline Note Reading & Staff & Pre-reading (no ledger line) \\
& 1) Treble Clef (RH only) - Piece 1 & 1) Black key (BH)- Piece 2 \\
& 2) Bass Clef (LH only) - Piece 2 & 2) White key (BH)- Piece 3-5 \\
& Grand Staff (BH)- Piece 3 & Grand Staff- Piece 6 \\
& onwards & Lead Sheet- Piece 56 and piece \\
& & 62 \\
\hline Rhythm/Note Value & Crotchet and Minim: piece 1 & Crochet, Minim, Dotted minim \\
& Semibreve: piece 2 & and semibreve: piece 2 \\
& Dotted Minim: piece 18 & Quaver: piece 21 \\
& Quaver: piece 37 & Tie note: piece 6 \\
& Dotted crotchet: piece 41 & Syncopated: piece 23 \\
& Tie note: piece 16 & \\
& Syncopated: piece 59 & \\
Triplet quavers: piece 73 & \\
Swing rhythm: piece 80 & \\
\hline Time Signature & 4/4: piece 4 & 4/4: piece 6 \\
& 3/4: piece 19 & 3/4: piece 8 \\
& 2/4: piece 43 & \\
\hline Intervals & 2nd and 3rd: piece 8 & 2nd and 3rd: piece 5 \\
& 4th and 5th: piece 12 & 4th: piece 42 \\
6th: piece 42 & 5th: piece 45 \\
& 7th and 8ve: piece 48 & 6th: piece 47 \\
\hline Articulation & Slur/legato: Piece 19 & Accent: piece 7 \\
Staccato: Piece 47 & Staccato: piece 18 \\
Accent: piece 61 &
\end{tabular}




\begin{tabular}{|c|c|c|}
\hline Scales & $\begin{array}{l}\text { C Major: piece } 51 \\
\text { G Major: piece } 57 \\
\text { F Major: piece } 61 \\
\text { A harmonic Minor: piece } 65 \\
\text { D harmonic minor: piece } 69\end{array}$ & $\begin{array}{l}\text { Penta C Major: piece } 31 \\
\text { Penta G Major: piece } 34 \\
\text { Penta A Major: exercise } \\
\text { C Major: piece } 49 \\
\text { G Major: piece } 57-64 \\
\text { Chromatic }\end{array}$ \\
\hline Chords & $\begin{array}{l}\text { I: piece } 14 \\
\text { V7: piece } 16 \\
\text { IV: piece } 21\end{array}$ & $\begin{array}{l}\text { I: piece } 16 \\
\text { V7: piece 50-52 } \\
\text { IV: piece 53-55 } \\
\text { Sus4: piece } 36\end{array}$ \\
\hline Key Signature & $\begin{array}{l}\text { C Major: piece } 51 \\
\text { G Major: piece } 57 \\
\text { F Major: piece } 61 \\
\text { A Minor: piece } 65 \\
\text { D Minor: piece } 69\end{array}$ & $\begin{array}{l}\text { C Major: piece } 1 \\
\text { G Major: piece } 57\end{array}$ \\
\hline Dynamic & $\begin{array}{l}\text { p: piece } 6 \\
\text { mf: piece } 7 \\
\text { f: piece } 8 \\
\text { ff: piece } 51 \\
\text { mp: piece } 67 \\
\text { pp: piece } 69 \\
\text { Crescendo e diminuendo: piece } 35\end{array}$ & $\begin{array}{l}\text { f: piece } 1 \\
\text { p: piece } 3 \\
\text { mf: piece } 12 \\
\text { mp: piece } 21 \\
\text { Crescendo e diminuendo: piece } \\
22 \\
\text { pp: piece } 59\end{array}$ \\
\hline
\end{tabular}

\section{Comparative Analysis on Technique}

Further comparative analysis on the techniques for both methods is examined to develop piano fundamental and comprehensive musicianship skills among non-piano majors. Table 4 presents the differences between the two methods.

Table 4 Comparative Analysis on the Technique

\begin{tabular}{lll}
\hline & ALFRED & FABER \\
\hline Transposition & No & Yes \\
\hline Rhythmic Exercise & Yes & Yes \\
\hline Improvisation & No & Yes \\
\hline Harmonization & Yes & Yes \\
\hline Study/Warm up Exercise & Intervals & Intervals \\
& Chords (Blocked and & Chords (Blocked and \\
& Broken) & Broken) \\
& Hanon 1, 2 & Penta-scale warm up \\
& & Octave warm up \\
\hline Sight Reading Exercise & & Accidentals warm up \\
\hline Arpeggios & No & Yes \\
& Yes & Yes \\
\hline Developing equal skills with all & Leschetizky Solution & No \\
fingers & & Crossing) \\
\hline
\end{tabular}




\begin{tabular}{lll}
\hline Scale & Yes & Yes \\
\hline Overlapping pedal & Yes & No \\
\hline Lead sheet & No & Yes \\
\hline
\end{tabular}

Music students are required to be able to demonstrate other acquired musical-related skills specifically: transposition, improvisation, sight-reading and harmonization skills. Mastery of these skills are proven to enhance students' musical instruments skills. All these techniques mentioned can be found clearly in Faber's method. In contrast, Alfred does not include any transposition, improvisation, and sight-reading exercise in its method.

Apart from these skills, the learning also enhances student's understanding on fundamental music such as music theory and aural skills. Music students are required to demonstrate these learning outcomes are stipulated in the program learning outcomes at the end of the study. The most interesting part of Alfred method includes an advance piano technique such as "The Amazing Aerobics of Hanon" and Leschetizky Solution. Other than that, Alfred provides an overlapping pedal technique in its method.

The similarities that can be found in the analysis are: 1) Both methods provide almost similar warm up exercise such as penta-scale, interval and chord warm up before start playing pieces. Both methods include the harmonization technique in the lesson. Also, each method includes scales and arpeggios technique. Each method includes scales and arpeggios technique. For Alfred, the arpeggios required one hand, meanwhile the Faber suggested two hand (involving hand crossing). Other than that, Alfred provides an overlapping pedal technique in its method.

\section{Comparative Analysis on Musical Theory}

The theoretical areas considered for the analysis include naming the notes, time signature, intervals, rule of stems, chord symbol, ear training, slur and ties, accidentals, triads, technical names and musical terminology as presented in Table 5 below.

Table 5 Comparative Analysis on Musical Theory

\begin{tabular}{lll}
\hline & ALFRED & FABER \\
\hline Naming the noes & Yes & Yes \\
\hline Time Signature & $\begin{array}{l}\text { Complete missing rhythm and } \\
\text { bar-lines }\end{array}$ & Write the counts \\
\hline Intervals & Yes & Yes \\
\hline Rule for Stems & No & Yes \\
\hline Chord Symbol & Pop & $\begin{array}{l}\text { Pop } \\
\text { Roman Numeral }\end{array}$ \\
\hline Ear Training & No & Yes \\
\hline Slur and Ties & Yes & No \\
\hline Writing Accidentals & Yes & No \\
\hline Scales & Write the scales & $\begin{array}{l}\text { Write the finger numbers of } \\
\text { the scale }\end{array}$ \\
\hline Triads/Chords & Yes & Yes \\
\hline $\begin{array}{l}\text { Technical name } \\
\text { (scale degree) }\end{array}$ & No & Yes \\
\hline
\end{tabular}




\begin{tabular}{lll}
\hline Musical terminology & Yes & Yes \\
\hline
\end{tabular}

Analysis shows that both methods contribute the similar theory lesson on 1) naming the notes, 2) time signatures, 3) intervals, 4) slur and ties, 5) scale and 6) triads and chord. Each of the theory pages in both methods provide drills and exercises to reinforce student's understanding on the concepts and principles. The interesting part about Faber, it provides dictionary on the musical terms at the end of the book. It is convenient for the music students to have a quick search for the musical signs and terms.

The differences found in the analysis are Alfred has additional theory lesson on the slur and ties, writing accidentals, and half step and whole step. Meanwhile, Faber provides additional theory lesson such as ear training, rules of stem and technical names. In terms of chords, Faber introduces a pop and a Roman numeral chord symbol, meanwhile, Alfred only utilizes a pop symbol. The interesting part about Faber, it provides dictionary on the musical terms at the end of the book. It is convenient for the music students to have a quick search for the musical signs and terms.

\section{The Strength and the Weakness of Each Methods}

This section presents the analysis on the strength and weaknesses of the methods as per the second study objective.

\section{Alfred's Basic Adult Piano Course}

The course begins very simply but progress quickly. Alfred is an instructive textbook, where a new concept introduced with detailed instructions. It provides simple exercise to practice/warm up for the new concept. Furthermore, there are no gaps between lesson, making the piano thorough and fluid. A systematic review of the material from earlier lessons is also carried out. At the end of the lesson, there are written assignments to reinforce what was just learn with additional of practice songs of increasing the difficulty in each lesson.

The content analysis shows that Alfred has a quick review of notes. It proceeds quickly through $\mathrm{C}$ position for each hand into Grand Staff. started with both hands almost from the beginning. In addition, the method is welldesigned where the first bar has the letters in the notes, then those letters disappear. The weakness of this technique, it uses a pre-set hand position. As a result, students more likely rely on the finger numbers and the notes direction instead of identifying each letter names.

Moreover, Alfred is quickly moved on to basic chords. It develops student's left hand for chording and linear accompaniment styles. This method offers students the chance to play the music with more proficient sound. Alfred does not provide optional teacher duet part. However, some edition includes CD and general MIDI accompaniment Disc with additional price.

Analysis reveals that Alfred has more scales to learn such as G, G, F Major and A, D harmonic minor aligned with the Course Learning Outcome for the Applied Piano Proficiency course. This technique may assist students to develop their major instrument skills, ear training and understanding on the music theory. The most interesting part of Alfred method, where it includes an advance piano technique such as "The Amazing Aerobics of Hanon" and Leschetizky Solution. Hanon is well-known preparatory exercise to acquire speed, precision, agility, and strength in the finger of both hands as well as flexibility of the wrist (Hanon, 1962). On top of that, "Leschetizky Solution" is one of the most effective exercises was specifically devised for developing skills and agility with all fingers and overcoming the problems of playing well with the most awkward fingers. (Palmer, et al 2007). 
Finding from the content analysis reveals that Alfred somehow has lack of some musical essential technique and exercises such as transposition, sight-reading, ear training and improvisation. Noticeable lack of creative activities like improvisation and composition and these tended not to be integrated within the main curriculum.

\section{Faber's Adult Piano Adventures All-In-One Course}

Faber has a well-organized lesson; students are introduced to new topics while integrating previous skills. Faber consist three skills integrated approach of reading: discreet note recognition, intervallic reading, and a multi-key understanding. This method reduces the student's dependence on pre-set hand positions. Furthermore, it teaches the fundamentals of transposition and basic chord recognition. However, Faber only introduced only two types of scale and key signature (C Major and G Major). Faber has the rhythm and note values (semibreve, dotted minim, minim, and crotchet) learnt quickly at the beginning of the book and stop at the introduction of the quaver in the middle of the book.

The most interesting part about the book is the "Analytical "Discovery" questions and "Creative" activities. It encourages in-depth study and enhance personal expression among the students. The area covered in this part includes a transposition, ear training, music theory, sight reading and improvisation. These type of activities and techniques are contributing to the fulfilment of the GPI's syllabus among undergraduate's non-piano majors. Next, an optional teacher duet part and the audio accompaniment tracks motivate students' musical expression, character and enhance melodic articulation. With these features, students also able to listen how the tunes are intended to sound. Moreover, the lesson become more interactive with the existing of decent harmonies. Some advance-level students may improve their reading when they have the opportunities of accompanying other students by playing the optional piano duet part.

Similar as Alfred, Faber also includes a discussion on the wrist movements. It highlighted the importance of having a relaxed wrist, the float-off technique, rotation of the wrist, and making half and full wrist circles.

Nevertheless, the progressive speed of Faber method may be slow, and students may feel frustrated to spend a lot of time on the physical exercises. Faber is introducing only two types of scale and key signature (C Major and G Major). Finding from the content analysis reveals that Faber has limited interval range, note value and rhythm which are the weakness of this method.

\section{Discussion}

The design of this GPI (course) is to introduce keyboard playing at a beginner-intermediate level. Both theoretical and practical aspects of music cover note reading, rhythm, scales, arpeggios, chord realization, transposition, and improvisation through three main learning outcomes:

CLO 1: Student should be able to demonstrate self-directed learning in rhythms, melodies, scales and arpeggios, chord progression and harmonies transposition, and improvisation.

CLO 2: Student should be able to perform solo and ensemble piano music with technical fluency at beginnerintermediate level.

CLO3: Student should be able to display sight-reading skills at a beginner-intermediate level.

Content analysis in both method books was examined and its relationship with respect towards attaining each course learning outcomes. Firstly, it is interesting to note that ninety percent are addressed in rhythm, melodies, chord progression and harmonization, transposition, and improvisation using Faber; and seventy-five percent is achieved in rhythm, melodies, scales and arpeggios, chord progression and harmonization using Alfred towards 
achieving the first course learning outcome for undergraduate's non-piano majors. Currently, Alfred method of learning is being used for teaching the non-piano major students; this implies that the Faber's method is proposed to be included in the learning-teaching instruction in the near future. Next, works for solo piano music is delivered and assessed except for ensemble piano music for both of these methods. This leads towards the attainment for the second learning outcomes. The significance of Faber method provides sight-reading exercise while Alfred does not. Thus, Faber provides value added learning on this aspect for non-piano major.

Alfred practices a combination of "intervallic and "Middle C" reading approach and its" approach to the chord is stronger than Faber. Alfred is progress quickly and appropriate for undergraduate non-piano majors as they have already possessed a basic musical knowledge and skills prior taking the GPI.

Nevertheless, Faber's involves more active fingers motion for both hands. Besides catered with a wide variety of music genre, Faber's contents are more accurate and demonstrated to accomplish the necessary musical skills (sight reading, ear training, transposition, and improvisation) required for the GPI among undergraduate's nonpiano majors. It contains a range of instructional materials such as creative learning activities and alternative features that promote students' engagement and interactive learning.

Alfred and Faber's method contain a comprehensive requirement scope and progression for a GPI. The methods are motivational, interesting, and are thoroughly concerned with the development of musical concepts. The two methods contain range of instructional materials, structured, clear, and logical progression of topics. Additionally, both methods presented a remarkable approach to teaching method by providing clear recommendations and helpful practice drills. Both methods present contents with much emphasis on the piano fundamental and theory, with a noticeable lack of piano ensemble activities. This implies the association between the content and its methods are inadequate to achieve one of the course learning outcomes, specifically "student should be able to perform solo and ensemble piano music with technical fluency at beginnerintermediate level".

\section{Conclusion and Recommendation}

In conclusion, both methods are relevant to the course (GPI); however, Alfred is being adopted at university level. This implies that the Faber's method is proposed to be included in the learning-teaching instruction in the near future. The study revealed that instruction through one method alone scarcely to match the GPI's intended learning outcomes due to various strengths and weaknesses of each methods. According to Barsamyan (2019), utilization of other resources that facilitate technical development will has positive effects on overcoming deficiency in method. Coutss in 2018 added that the selection of the repertoire by the teachers/educators must align with student's tastes and goals, and to understand the impact of student's values, expectations, and perceptions of learning on their engagement with repertoire learned. Hence, it is recommended for a future indepth research to be carried out to investigate the effectiveness of these two methods to support this study.

\section{References}

Amoriello, L. (2010). "Teaching undergraduate class piano: A study of perspectives from self, students, and colleagues." Available from ProQuest Dissertations Publishing. (UMI No. 3424999).

Anonymous. (1915). Passing of the world's most famous piano teacher. (1915). 100 Years Ago...In Musical America, 3. Retrieved from

https://www.musicalamerica.com/pages/index.cfm?pagename=11-27-1915_p3\&historical

Barsamyan, M. (2019). Piano education in adults. Educational Research and Reviews, 14(13), 458-464.

Beres. K. (1999). Colleges from the perspective of the "effectiveness in instruction on performance skills", Study of School Music Education, 11, pg. 69-70.

Bianchi, L. (1978). For Success: Make your program match your group. Piano Quarterly, 101, pg. 19-22. 
Callahan, M.R. (2015). Teaching and Learning Undergraduate Music Theory at the Keyboard: Challenges, Solutions, and Impacts. Music Theory Online, 21. DOI: 10.30535/mto.21.3.4. Retrieved from 12th September 2020.

Chen, Y.C., Penick, A.W., Gille, T.L., Johnson, W.M., Fleming, S., \& Crystal, R. (2013). A comparison of the music tree, piano adventures, and hal leonard student library for beginning piano teachers. (Doctoral dissertation, University of Alabama Tuscaloosa, Alabama). 61741701.

Chiu, P.Y. (2017). "A comparative evaluation of group and private piano instruction on the musical achievements of young beginners." PhD diss., University of Washington. Available from ProQuest Dissertations and Theses Global.

Coutts, L. (2018). Selecting motivating repertoire for adult piano students: A transformative pedagogical approach. British Journal of Music Education. 35 (3), 285-299. DOI: 10.1017/S0265051718000074.

Ernst, R.E. \& S. Emmons (1992). New horizons for senior adults. Music Educators Journal, 79, 30-34.

Faber, N., Faber, R. (2016). Adult Piano Adventures: All-in-One Course Book 1. Michigan: Faber Piano Adventures; 2nd Edition.

Fisher, Christopher (2010). Teaching Piano in Groups. New York, New York: Oxford University Press. pp. 37.

Fuchs, I. (2009) "Aus Carl Czernys Korrespondenze", in Heinz von Loesch, Karl Czerny: Componist, pianist und pedägoge. Schott: 139 .

Hall, D. (n.d). Piano method books - A brief history. Retrieved from https://www.palomapiano.com/blogpost/piano-method-books-a-brief-history/

Hanon, C.L. (1962). Junior Hanon. Georgia: Alfred Music; 57350th Edition.

Johnson, R. (1981). Group lessons: They're not just for beginners. Clavier, 20 (10) pg. 27.

Kowalchyk, G. and Lancestor, E.L (1997). Group piano course. Alfred Music Publishing.

Lancestor, E.L and Renfrow K.D. (1955). Group piano for adults. book 1, edition 2. Alfred Music Publishing.

Nakagawa, K. (2007). Effectiveness of group lessons on singing in teacher training colleges from the perspective of the "effectiveness in instruction on performance skills", Study of School Music Education, $11 \mathrm{pg}$. 69-70

Palmer W.A., Manus, M., Lethco, A.V. (2005). Alfred's Basic Adult All-in-One Course, Book 1. U.S.A: Alfred Music; Spi Edition.

Rainbow, B. (1990). Johann Bernhard Logier and the Chiroplast Controversy. The Musical Times, 131(1766), 193-196. doi:10.2307/966259.

Richards, W.H. 1962. Trends of piano class instruction, (Doctoral dissertation, University of Missouri at Kansas City, 1962). Dissertation Abstracts International 28, 712. (18151962).

Schons, S. M. (2005). Piano teachers' attitudes on piano pedagogy course topics (Doctoral dissertation, The University of Oklahoma.

Skroch, D. (1991). "A descriptive and interpretive study of class piano instruction at four-year colleges and universities accredited by the National Association of Schools of Music with a profile of the class piano instructor." PhD diss. University of Oklahoma. Dissertation Abstracts International 52, 3854.

Swinkin, J. (2007) "Keyboard fingering and interpretation: A comparison of historical and modern approaches," Performance Practice Review: Vol. 12: No. 1, Article 1. DOI: 10.5642/perfpr.200712.01.01. Retrieved from 31st July 2020.

Wristen, B. (2006) "Demographics and motivation of adult group piano students." Music Education Research. 8 (3), 4.

Young, M. M. (2013). University level group piano instruction and professional musicians. Music Education Research, 15(1), 59-73. DOI: 10.1080/14613808.2012.737773. Retrieved from August 30, 2020.

Zakaria, J., Mahzair, A.M. (2018). The effectiveness of group piano instruction for non-piano music majors. In Rahman, M.K.A, C.S.C. Chan, Saidon, Z.L, Augustine, C. \& Maniam, S. (Eds.), Proceedings of the 3rd International Music and Performing Arts Conference (pp.97). Tanjong

Malim: Faculty of Music and Performing Arts, Universiti Perguruan Sultan Idiris, 